\title{
Differentiation of Bacillus anthracis from Other Bacillus cereus Group Bacteria with the PCR
}

\author{
I. HENDERSON, ${ }^{1 *}$ C. J. DUGGLEBY, ${ }^{2}$ AND P. C. B. TURNBULL ${ }^{1}$ \\ Division of Biologics ${ }^{1}$ and Division of Biotechnology, ${ }^{2}$ Public Health Laboratory Service, Centre for \\ Applied Microbiology and Research, Porton Down, Salisbury SP4 0JG, England
}

\begin{abstract}
Variation among isolates of Bacillus anthracis was examined by using restriction fragmentation patterns and the PCR performed with arbitrary and sequence-specific oligonucleotide primers. The patterns were compared with the patterns generated from strains of closely related species belonging to the "Bacillus cereus group" of bacteria, including $B$. cereus, Bacillus thuringiensis, and Bacillus mycoides. All $B$. anthracis profiles were identical for each of 18 restriction enzymes, each of 10 arbitrary PCR primers, and a repetitive extragenic palindrome-specific PCR primer. The PCR profiles generated with a coliphage M13-based primer exhibited slight pattern variation in a 400 - to 500 -bp band region. The $B$. anthracis profiles were unique compared with the profiles of the other species examined. In these other species, strain-to-strain variations were observed. Our results showed that isolates of $B$. anthracis are almost completely homogeneous, indicating a clonal lineage, and are distinct from other members of the $B$. cereus group and that $B$. anthracis, as a species in its own right, may have evolved only relatively recently.
\end{abstract}

DNA homology studies $(11,24)$ have shown that Bacillus anthracis is closely related to Bacillus cereus, Bacillus thuringiensis, and Bacillus mycoides. These species have almost identical $\mathrm{G}+\mathrm{C}$ contents (31 to $34 \mathrm{~mol} \%$ ) (15), and ribosomal DNA sequence data have revealed only minor differences among them $(1,2)$. In the laboratory, confirmation of suspect isolates as $B$. anthracis is generally accomplished by using tests for gamma phage susceptibility, penicillin susceptibility, motility ( $B$. anthracis is not motile), hemolysis (absent or delayed in $B$. anthracis), and the production of capsule and toxin gene products.

Textbook methods for the identification of $B$. anthracis are based on biochemical and serological techniques (reviewed in reference 29), but in practice, the sharing of biochemical and antigenic properties by members of the " $B$. cereus group" is such that these techniques are not reliable for distinguishing one member of the group from another. The main difference between $B$. anthracis and other members of the $B$. cereus group is the presence of two virulence plasmids, pXO1 (which codes for toxin production) and pXO2 (which codes for capsule production). The PCR has been used to detect virulence plasmid genes and is important for the detection of virulent forms of $B$. anthracis in the environment $(7,27)$. However, the inability of this technique to detect plasmid-free strains that may have arisen from virulent precursors should be kept in mind (29). The basis for distinguishing such plasmid-free isolates from $B$. cereus rests on the gamma phage susceptibility, motility, and hemolysis tests mentioned above.

The ability to distinguish strains of $B$. anthracis is also important for both epidemiological purposes and quality control of vaccine seed cultures $\left(\mathrm{pXO}^{+}{ }^{+} \mathrm{pXO2}{ }^{-}\right)$. To date, this has not been possible because of the conserved nature of the species and the phenotypic overlap with other members of the $B$. cereus group. Therefore, there is an urgent need for

${ }^{*}$ Corresponding author. Mailing address: Anthrax Section, Division of Biologics, PHLS Centre for Applied Microbiology and Research, Porton Down, Salisbury, Wiltshire SP4 0JG, United Kingdom. Phone: 0980 612372. Fax: 0980610898. a way to specifically identify all forms, virulent and avirulent, of $B$. anthracis and for a way to distinguish strains within the species.

One technique to determine interrelationships which has been successfully used for gram-positive organisms (19) and in particular for $B$. thuringiensis (18) is DNA fingerprinting using probes that detect restriction fragment length polymorphisms. Differences between organisms, as reflected in the frequency and intersequence heterogeneity of specific repeated sequences distributed throughout the genome, can be revealed by Southern blotting of cleaved DNA with appropriate probes. An alternative way to fingerprint genomes is with the PCR, by using either the randomly amplified polymorphic DNA analysis technique (32) or sequence-specific primers. This method has been used to amplify speciesspecific sequences for the detection of clinically important food-borne pathogens (16) and in environmental surveillance studies (3). Randomly amplified polymorphic DNA PCR methods have been used to differentiate species and strains with oligonucleotide primers with arbitrary sequences and have been used to differentiate Lactococcus lactis (6) and Clostridium difficile (17). The principal advantages of this technique are its reproducibility and the lack of a requirement for a detailed knowledge of the genomic organization of the target organism.

The primary focus of this study was to demonstrate differences between isolates of $B$. anthracis at the genetic level for the purposes of (i) reliable and consistent differentiation from other species belonging to the $B$. cereus group, (ii) epidemiological comparison of isolates obtained from outbreaks of anthrax, and (iii) monitoring variations known to occur in vaccine seed strains for quality control purposes.

\section{MATERIALS AND METHODS}

Bacterial strains and culture conditions. The bacterial strains used in this study are listed in Table 1. All strains were inoculated into $100 \mathrm{ml}$ of $\mathrm{L}$ broth and grown with shaking $(200 \mathrm{rpm})$ for $8 \mathrm{~h}$ at $37^{\circ} \mathrm{C}$.

DNA isolation. The method of Marmur (14) was modified 
TABLE 1. Origins and characterization of the strains used in this study ${ }^{a}$

\begin{tabular}{|c|c|c|c|}
\hline B. anthracis isolate(s) ${ }^{b}$ & Other designation & Otigin, year of isolation, and/or other information ${ }^{c}$ & Reference(s) \\
\hline NCTC 8234 & Sterne $^{d}$ & $\begin{array}{l}\text { Cow, South Africa, 1937, } \mathrm{pXO1}^{+} \mathrm{pXO}^{-} \text {human vaccine } \\
\text { strain }\end{array}$ & \\
\hline ASC 97 & Sterne ${ }^{e}$ & $\begin{array}{l}\text { Cow, South Africa, } 1937, \mathrm{pXO1}^{+} \mathrm{pXO2}^{-} \text {human vaccine } \\
\text { strain }\end{array}$ & 26 \\
\hline ASC 47 & & Animal vaccine strain $f$ & 12 \\
\hline ASC 68 & Ames & Cow, United States, 1980 & \\
\hline ASC 162, ASC 167 & & Guinea pig reisolates of ASC 68 & 29 \\
\hline NCTC $10340^{\mathrm{T}}$ & Vollum & Cow, United Kingdom, pre-1939 & 25 \\
\hline ASC 69 & New Hampshire & Human, United States, 1957 & 22 \\
\hline ASC 182 & Pasteur & France, pre-1880s & 21 \\
\hline $\begin{array}{l}\text { ASC } 27, \text { ASC } 28, \text { ASC } 29, \\
\text { ASC } 30, \text { ASC } 31\end{array}$ & & Cattle, United Kingdom, from West Africa, 1977 or 1978 & 13 \\
\hline ASC 58, ASC 60 & & Elephant, Namibia, 1983 & 28 \\
\hline $\begin{array}{l}\text { ASC 50, ASC 52, ASC 54, } \\
\text { ASC 55, ASC 56, ASC } 189\end{array}$ & & Human epidemic, Zimbabwe, 1982 & 9,10 \\
\hline ASC 234 & & Sewage, 1992 & \\
\hline ASC 122 , ASC 126 & & $\mathrm{pXO1}^{-} \mathrm{pXO}^{-}$sewage isolates, United Kingdom, 1989 & 33 \\
\hline ASC 101, ASC 103 & & $\mathrm{pXO1}^{+} \mathrm{pXO2}-$ tannery dump isolates, 1988 & \\
\hline ASC 184 & Cured Vollum isolate $\mathrm{g}$ & $\mathrm{pXO1}^{+} \mathrm{pXO}^{-}$ & \\
\hline ASC 185 & Cured Vollum isolates ${ }^{g}$ & $\mathrm{pXO1}^{-}, \mathrm{pXO}^{+}$ & \\
\hline NCTC 5444 & & United Kingdom, 1938 & 20 \\
\hline ATCC 938 & & Human, United Kingdom, 1931 & 8 \\
\hline ASC 65 & & Cow, Brazil, 1982 & 5 \\
\hline ASC 112 , ASC 114 & & $\mathrm{pXO1}^{-} \mathrm{pXO} 2^{-}$sewage isolates, United Kingdom, 1988 & \\
\hline ASC 327 & Vollum ${ }^{g}$ & $\mathrm{pXO1}^{-} \mathrm{pXO}^{-}$ & \\
\hline ASC 328 & Vollum $s$ & $\mathrm{pXO1}^{+} \mathrm{pXO}^{+}$ & \\
\hline ASC 183 & & $\mathrm{pXO1}^{-} \mathrm{pXO2}{ }^{+}$penicillin-resistant isolate, $1976^{h}$ & 25 \\
\hline ASC 45 & Sterne & & 12 \\
\hline
\end{tabular}

${ }^{a}$ The following other members of the B. cereus group were also used in this study: B. cereus NCTC $2599^{\mathrm{T}}$ (T = type strain), NCTC 7464, and NCTC 9939; B. cereus F4810/72, F4433/73, F2532/74, and F8035, obtained from the Food Hygiene Laboratory, Central Public Health Laboratory, Colindale, London, England; B. mycoides NCTC 09680; B. thuringiensis HD37, HD102, and HD225, obtained from H. T. Dulmage, U.S. Department of Agriculture, Brownsville, Tex.; and B. thuringiensis F2110/78 (subsp. kenyae) and F2113/78 (subsp. entomocidus), obtained from the Food Hygiene Laboratory, Central Public Health Laboratory, Colindale, London, England.

${ }^{b}$ ASC, Anthrax Section culture, Division of Biologics, Public Health Laboratory Service Centre for Applied Microbiology and Research, Porton Down, Salisbury, England; ATCC, American Type Culture Collection, Rockville, Md.; NCTC, National Collection of Type Cultures, London, England.

$c$ Unless stated otherwise, all $B$. anthracis isolates are $\mathrm{pXO1}^{+} \mathrm{pXO}^{+}$.

d Original Sterne vaccine strain.

$e$ Wellcome vaccine strain.

${ }^{f}$ Romanian Stamatin animal vaccine strain (designated strain B1119 by Logan et al. [12]).

$g$ Defence Microbiology Division, Chemical and Biological Defense Establishment, Porton Down, Salisbury, England.

${ }^{h}$ ASC 32 cured of the appropriate plasmid by C. P. Quinn, Division of Biologics, Public Health Laboratory Service Centre for Applied Microbiology and Research, Porton Down, Salisbury, England.

to overcome problems with lysis of $B$. anthracis cells. Briefly, cells from $8-\mathrm{h} 100-\mathrm{ml}$ cultures $\left(A_{600}, 2.0\right)$ were pelleted by centrifugation at $10,000 \times g$ and resuspended in $5 \mathrm{ml}$ of $0.1 \mathrm{M}$ potassium phosphate buffer $(\mathrm{pH} \mathrm{6.8)}$. After the addition of mutanolysin (final concentration, $100 \mathrm{U} / \mathrm{ml}$; Sigma) and incubation at $37^{\circ} \mathrm{C}$ for $1 \mathrm{~h}$, lysozyme (Sigma) was added to a concentration of $0.2 \mathrm{mg} / \mathrm{ml}$, and incubation was continued for an additional $1 \mathrm{~h}$, after which the suspension was heated at $60^{\circ} \mathrm{C}$ for $5 \mathrm{~min}$. The cells were lysed by adding 0.05 volume of a warm $\left(60^{\circ} \mathrm{C}\right) 25 \%(\mathrm{wt} / \mathrm{vol})$ sodium dodecyl sulfate solution; after $5 \mathrm{~min}$ at $60^{\circ} \mathrm{C}$, the cell lysate was allowed to cool to the ambient temperature. Proteins were removed by phenol extraction, and the DNA was collected by spooling with cold absolute ethanol (23). After resuspension in TE buffer (10 mM Tris-Cl [pH 8.0], $1 \mathrm{mM}$ EDTA), RNA was removed by adding DNase-free RNase (final concentration, $1 \mu \mathrm{g} / \mathrm{ml}$; Boehringer) and incubating the preparation at $37^{\circ} \mathrm{C}$ for $1 \mathrm{~h}$. The DNA solution was reextracted once with phenol and then three times with chloroform-isoamyl alcohol $(24: 1, \mathrm{vol} / \mathrm{vol})$. The DNA was collected by spooling with isopropanol, washed for $5 \mathrm{~min}$ in increasing concentrations of ethanol (70 to $100 \%$, vol/vol), dried, and finally resuspended in a minimum volume of TE buffer.
Restriction enzyme digestion. The restriction enzymes used to digest total cellular DNA were $A l u \mathrm{I}$, DraI, DraII, EcoRI, EcoRV, HaeII, HaeIII, HindIII, HinfI, HpaI, HpaII, PstI, PvuII, Sau3AI, SinI, StyI, TaqI, and XbaI. In each case, 5 $\mu g$ of DNA was digested with the restriction enzyme in accordance with the instructions of the manufacturer (Northumbria Biologicals Ltd., Cramlington, United Kingdom). Digests were heated to $70^{\circ} \mathrm{C}$ prior to analysis by electrophoresis (23).

Oligonucleotides. Oligonucleotides were synthesized with an Applied Biosystems model 380B DNA synthesizer by using the automated phosphoramidite coupling method or were obtained directly from Alta Biosciences, Edgbaston, United Kingdom. The following arbitrary oligonucleotide primers were used in this study: (i) 5'-TCGAGCTT-3', (ii) 5'-GAGCTGACCA-3', (iii) 5'-CGTAACGACGTC-3', (iv) 5'-CTTCAGATAGACACG-3', (v) 5'-TGAATGAAGCCAT ACCAA-3', (vi) 5'-GTATTGTTAACCCAACTG-3', (vii) 5' GTATGAGTATTCAACATTC-3', (viii) 5' -ATAAATAAAA TATATTCAAAAA-3', (ix) 5'-AAGTTGACAAAATTATT TAAG-3', and (x) 5'-TGAAGATAAAAATATTGTTTTTA $3^{\prime}$. The following sequence-specific primers were used: (i) $5^{\prime}$-GAGGGTGGCGGCTCT-3', taken from the sequence of the M13 fingerprinting probe first identified by Vassart et al. 


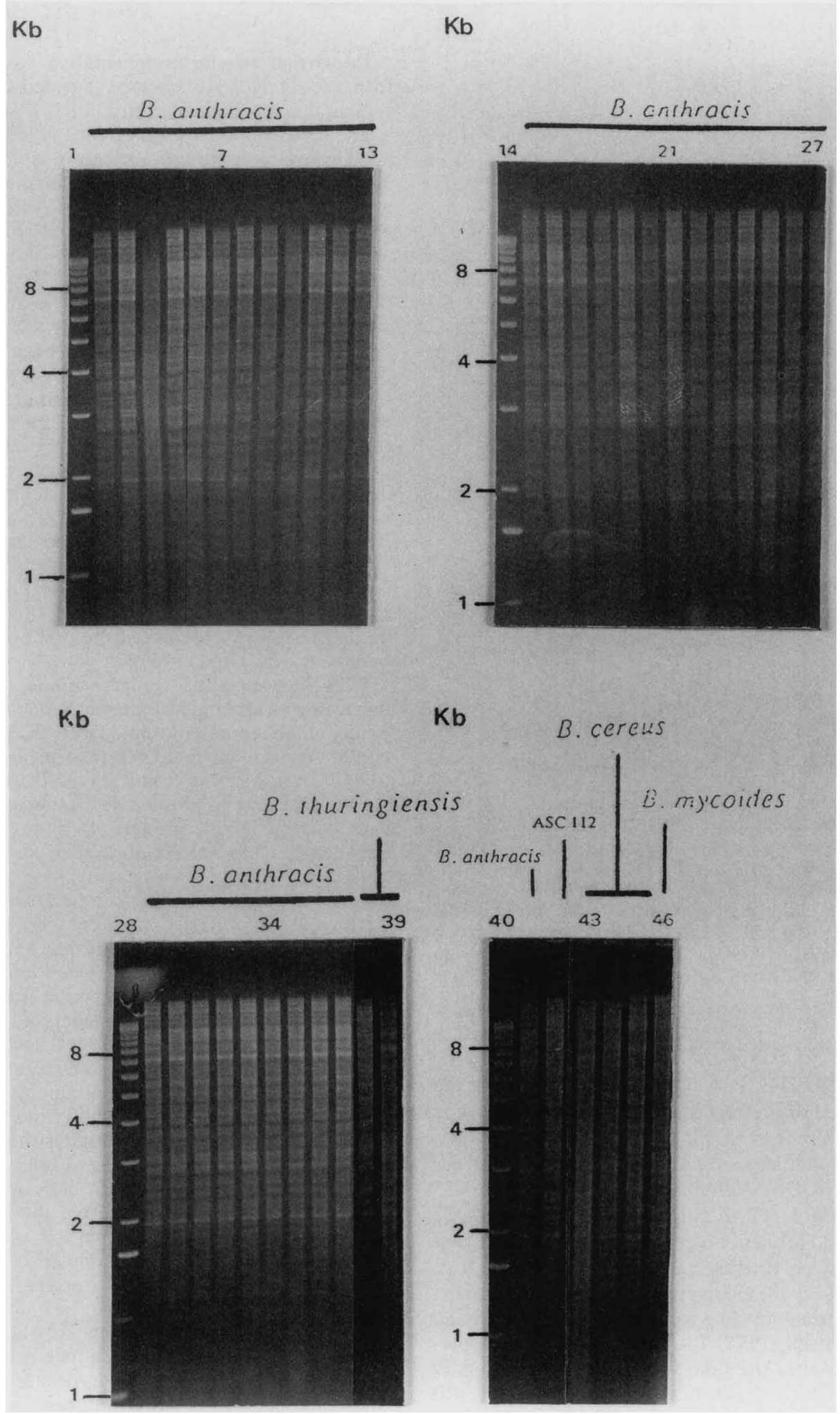

FIG. 1. EcoRI digests of total DNAs from members of the B. cereus group. DNA was separated by electrophoresis on a $0.7 \%$ agarose gel at $2.5 \mathrm{~V} / \mathrm{cm}$. Lanes $1,14,28$, and 40, kilobase ladder; lanes 2 through 13, B. anthracis ASC 50, ASC 52, ASC 54, ASC 55, ASC 56, ASC 189, ASC 234, ASC 122, ASC 126, ASC 101, ASC 103, and ASC 327, respectively; lanes 15 through 27, B. anthracis ASC 184, ASC 185, ASC 328, ASC 68, ASC 162, ASC 167, NCTC $10340^{\mathrm{T}}$, ASC 69, ASC 182, ASC 27, ASC 28, ASC 29, and ASC 30, respectively; lanes 29 through 37 , B. anthracis ASC 31, ASC 65, ASC 45, ASC 60, NCTC 8234, ASC 97, ASC 47, ASC 58, and ASC 183, respectively; lanes 38 and 39 , $B$. thuringiensis HD 37 and F2110/78, respectively; lane 41, B. anthracis NCTC $10340^{\mathrm{T}}$; lane 42, ASC 112; lanes 43 through $45, B$. cereus NCTC $2599^{\mathrm{T}}$, NCTC 7464, and F4810/72, respectively; lane 46, B. mycoides NCTC 09680. 


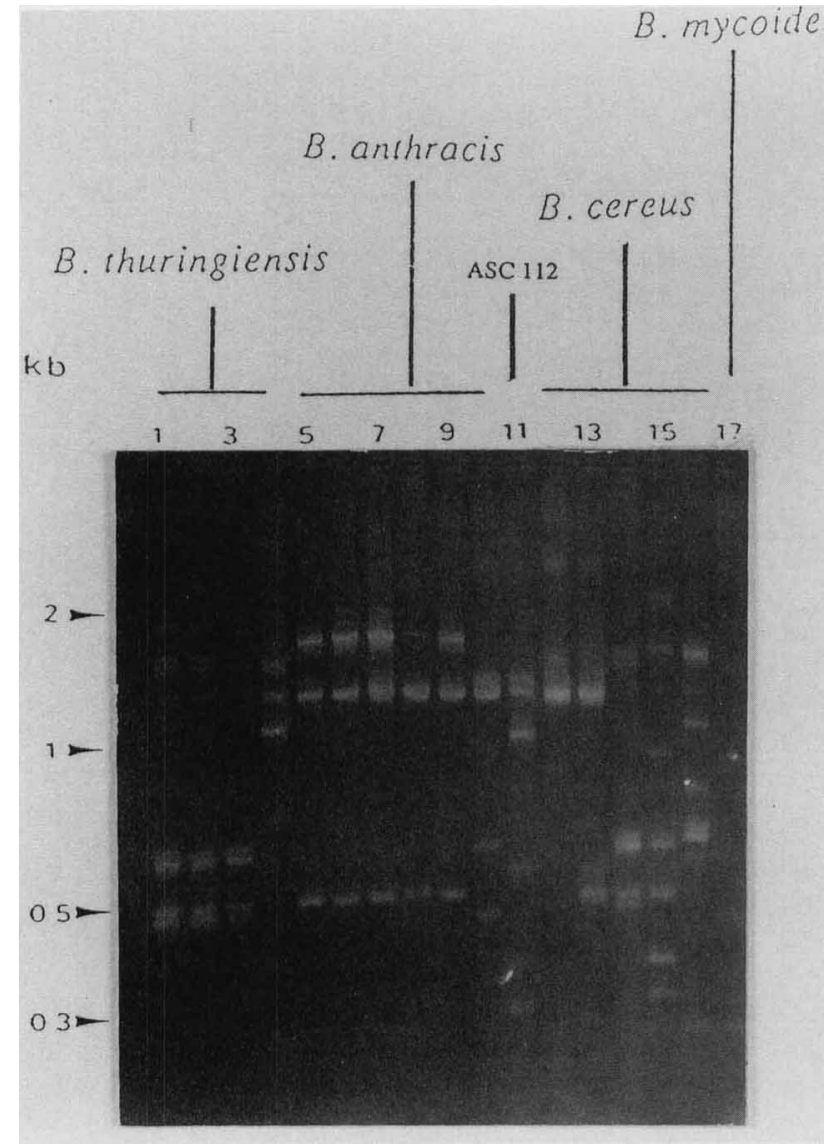

FIG. 2. PCR fingerprinting of $B$. cereus group strains performed with the sequence-specific primer 5'-IIIICGICGICATCIGGC-3'. PCR products were separated by electrophoresis on a $2 \%$ agarose gel at $2.5 \mathrm{~V} / \mathrm{cm}$. Lane 1, 1-kb ladder; lanes 2 through $5, B$. thuringiensis HD37, HD102, HD225, and F2113/78, respectively; lanes 6 through $11, B$. anthracis NCTC 8234, NCTC $10340^{\mathrm{T}}$, ASC 68, ASC 69, ASC 182, and ASC 112, respectively; lanes 12 through 16, B. cereus F2532/79, F4810/72, F4433/78, NCTC $2599^{\mathrm{T}}$, and NCTC 9939, respectively; lane 17, B. mycoides NCTC 09680 .

(30), and (ii) 5'-IIIICGICGICATCIGGC-3', taken from the consensus sequence of the repetitive extragenic palindrome described by Versalovic et al. (31).

PCR reaction conditions. Each PCR mixture $(100 \mu \mathrm{l})$ contained $150 \mathrm{ng}$ of DNA template, $1.25 \mathrm{mM}$ dATP, 1.25 $\mathrm{mM}$ dCTP, $1.25 \mathrm{mM}$ dGTP, $1.25 \mathrm{mM}$ dTTP, $3.0 \mathrm{mM} \mathrm{Mg}^{2+}$, each oligonucleotide primer at a concentration of $2 \mu \mathrm{M}$, and 2.5 U of Taq DNA polymerase. The primers were used (i) singly, (ii) in pairs, or (iii) in several different combinations. The following thermal cycling conditions were used: an initial denaturation step $\left(95^{\circ} \mathrm{C}\right.$ for $10 \mathrm{~min}$; Taq DNA polymerase was added after the first $5 \mathrm{~min}$ of this step) and 39 cycles consisting of (i) denaturation at $96^{\circ} \mathrm{C}$ for $1 \mathrm{~s}$, (ii) annealing at $30^{\circ} \mathrm{C}$ for $10 \mathrm{~s}$, and primer extension at $72^{\circ} \mathrm{C}$ for $10 \mathrm{~s}$. Samples were overlaid with $100 \mu \mathrm{l}$ of mineral oil to minimize evaporation during thermal cycling. When the PCR was completed, the samples were frozen at $-20^{\circ} \mathrm{C}$ to allow removal of the mineral oil without loss of sample; once the samples were thawed, they were analyzed by electrophoresis $(23)$.

\section{RESULTS}

Restriction enzyme fragmentation patterns. Total DNAs from the Bacillus strains were digested with each enzyme; a typical result (obtained with EcoRI) is shown in Fig. 1. For a given restriction enzyme, the patterns obtained for all specifically identified $B$. anthracis isolates were identical. The patterns obtained for other members of the $B$. cereus group were different from the $B$. anthracis pattern and exhibited strain-to-strain differences (Fig. 1, lane 11). One strain included in this study was ASC 112, which was isolated from a site in the United Kingdom that was suspected of being contaminated with anthrax spores. This isolate was morphologically similar to $B$. anthracis but was found to be resistant to gamma phage and penicillin (and hence would normally be regarded as $B$. cereus). The restriction enzyme fragment pattern of the DNA from this isolate was almost indistinguishable from the patterns of the other $B$. anthracis isolates, but a careful examination of certain bands revealed slight differences, indicating that this isolate may represent a naturally occurring hybrid or intermediate between $B$. anthracis and other members of the $B$. cereus group. The inability to specifically identify differences between confirmed $B$. anthracis isolates and the presence of isolates such as ASC 112 indicate that our method is inadequate for specifically and unequivocally differentiating $B$. anthracis from other closely related members of the $B$. cereus group.

PCR fingerprinting. Fingerprinting of $B$. cereus group bacteria was attempted by using sequence-specific and randomly amplified polymorphic DNA PCR methods. The PCR conditions used included various annealing temperatures $(30$ to $\left.65^{\circ} \mathrm{C}\right)$ and $\mathrm{Mg}^{2+}$ concentrations $\left(0.5\right.$ to $\left.5.0 \mathrm{mM} \mathrm{Mg}{ }^{2+}\right)$ in the PCR mixture to provide the best possible fingerprint with each oligonucleotide primer. No differences were observed between $B$. anthracis isolates when we used arbitrary primers, either singly or in combination with other primers (multiplex), at the annealing temperatures and $\mathrm{Mg}^{2+}$ concentrations at which DNA products were formed. Differences were observed between $B$. anthracis and the other members of the $B$. cereus group and between individual strain types, as previously found with restriction fragmentation patterns (Fig. 2). The profiles of PCR-generated DNA fragments for these species and strains did reveal some band sharing with B. anthracis, but the profiles were more complex and readily distinguishable. When this technique was used, isolate ASC 112 could be readily distinguished from $B$. anthracis strains, including those $B$. anthracis isolates that lacked one or both of the virulence plasmids. These results demonstrate that the PCR fingerprint obtained for $B$. anthracis is independent of virulence status and distinct from the fingerprints of other members of the group. This method has the advantage that fingerprint profiles are much simpler to read than restriction fragmentation patterns and results can potentially be achieved much more rapidly.

One of the two sequence-specific oligonucleotide primers used, the M13 consensus sequence primer (5'-GAGGGTG GCGGCTCT-3'), yielded fingerprints that revealed minor differences between the $B$. anthracis isolates. These polymorphisms (Fig. 3 and 4) probably represent small differences, either at the primer binding site or in the spaces between putative PCR primer binding sites. On the basis of these differences, $B$. anthracis isolates were divided into three groups (Table 2). These groups are not related to virulence status, infected host species, or geographical origin. 


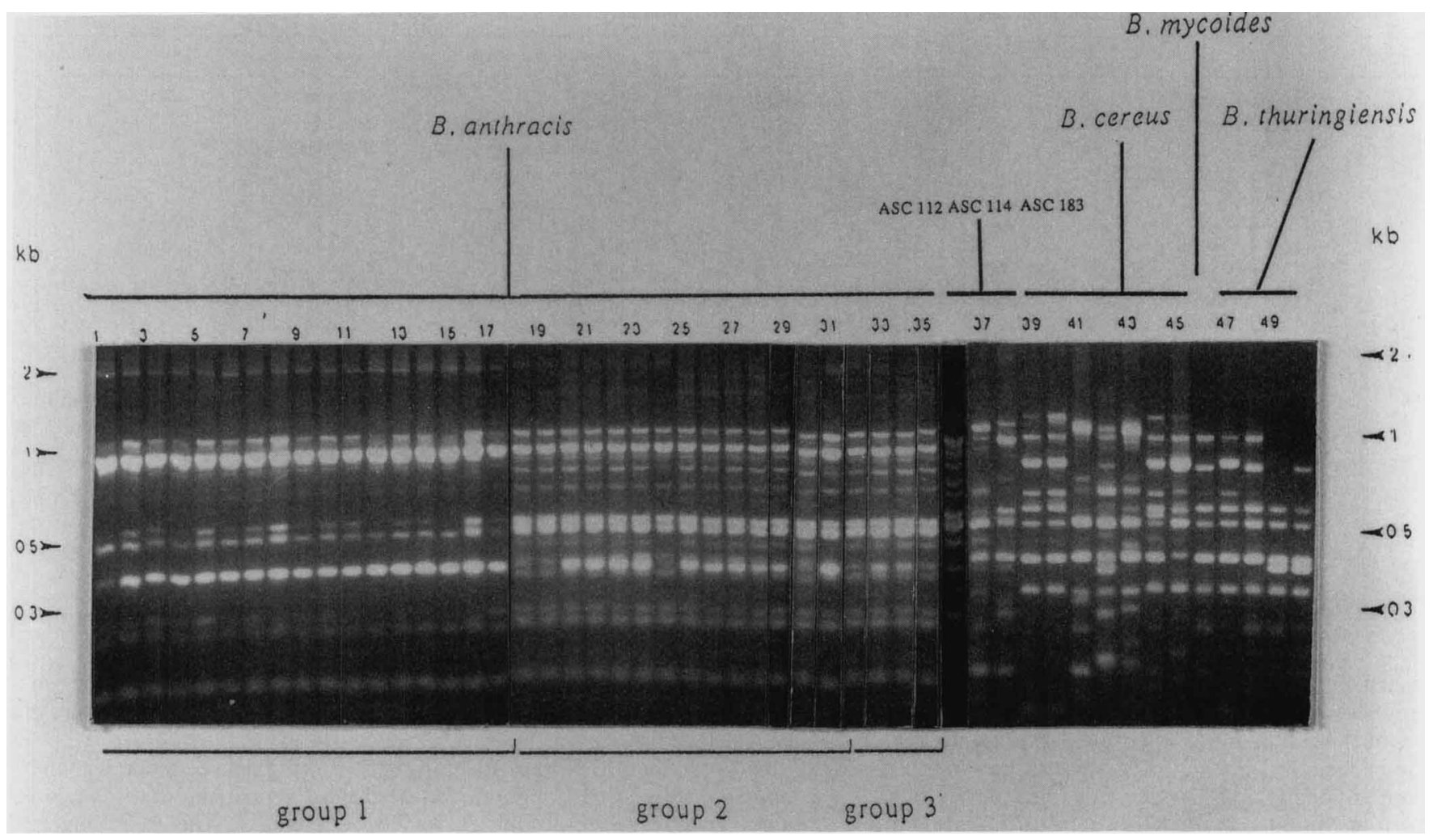

FIG. 3. PCR fingerprinting of $B$. cereus group strains performed with the M13 consensus sequence primer 5'-GAGGGTGGCGGCTCT-3'. PCR products were separated by electrophoresis on a $2 \%$ agarose gel at $2.5 \mathrm{~V} / \mathrm{cm}$. Lanes 1 through 17 , group $1 \mathrm{~B}$. anthracis isolates ASC 50, ASC 52, ASC 54, ASC 55, ASC 56, ASC 189, ASC 234, ASC 122, ASC 126, ASC 101, ASC 103, ASC 327, ASC 184, ASC 185, ASC 328, NCTC 5444, and ATCC 938, respectively; lanes 18 through 31, group 2 B. anthracis isolates ASC 68, ASC 162, ASC 167, NCTC 10340 ${ }^{\mathrm{T}}$, ASC 69, ASC 182, ASC 27, ASC 28, ASC 29, ASC 30, ASC 31, ASC 65, ASC 45, and ASC 60, respectively; lanes 32 through 35, group 3 B. anthracis isolates NCTC 8234, ASC 97, ASC 47, and ASC 58, respectively; lanes 36 through 38, strains ASC 112, ASC 114, and ASC 183, respectively; lanes 39 through $45, B$. cereus NCTC $2599^{\mathrm{T}}$, NCTC 7464, F4810/72, F4433/73, F2532/74, 8035, and NCTC 9939, respectively; lane 46, B. mycoides NCTC 09680; lanes 47 through 50, B. thuringiensis HD 37, HD 102, F2110/78, and F2113/78, respectively.

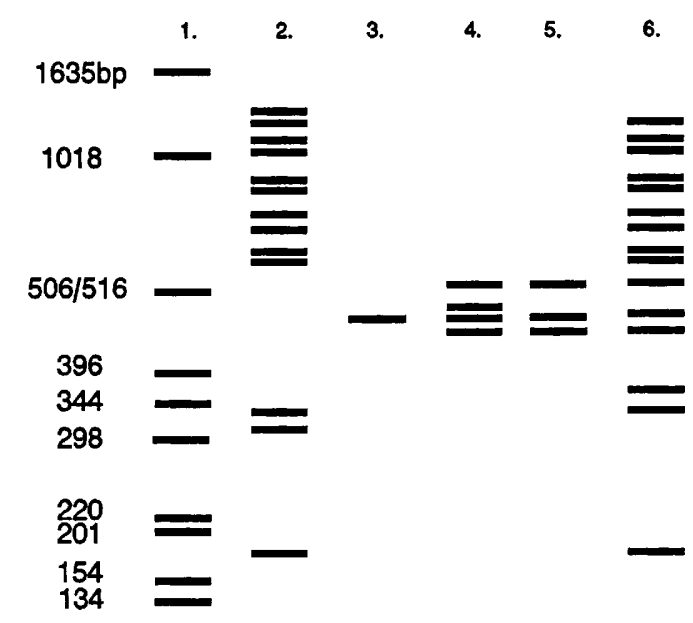

FIG. 4. Schematic representation of the variable regions in the PCR fingerprints of $B$. anthracis strains determined with the M13 consensus sequence primer. Lane 1, 1-kb ladder; lane 2, bands common to all $B$. anthracis isolates; lane 3, bands found in group 1 isolates; lane 4, bands found in group 2 isolates; lane 5, bands found in group 3 isolates; lane 6, fingerprint of ASC 112. The strains in each group are shown in Table 2.

\section{DISCUSSION}

The importance of $B$. anthracis as a pathogen requires that a means be sought for both specific identification and differentiation of this taxon from the other members of the closely related $B$. cereus group and subdifferentiation of the species into strains for epidemiological and other purposes. For microbiologists familiar with the $B$. cereus group, members of this group are normally fairly simple to identify in the laboratory. The high degree of sharing of phenotypic characteristics within the group means that further identification of $B$. anthracis and $B$. thuringiensis is based on the detection of virulence factors (i.e., capsule and toxin production in $B$. anthracis and parasporal crystal proteins in $B$. thuringiensis). However, with $B$. anthracis, the existence of avirulent "anthrax-like" organisms in the environment that lack the genes for toxin and/or capsule production can easily defeat such techniques. A more sensitive and revealing approach to identification and differentiation is to assess genome structure. In this study, this approach took the form of an analysis of restriction enzyme digestion patterns of isolated total DNAs; we also examined the more complex aspects of specific sequence distribution that were revealed by DNA fingerprinting with the PCR.

A simple comparison of restriction fragment patterns revealed that at this level of differentiation, B. anthracis is homogeneous and that differences between virulent and 
TABLE 2. B. anthracis groups as determined by M13 PCR fingerprinting

\begin{tabular}{|c|c|c|c|c|}
\hline Group & Strain(s) & Geographical origin & Source & Other designation \\
\hline \multirow[t]{10}{*}{1} & ASC 50, ASC 52, ASC 54, ASC 55, ASC 56, ASC 189 & Africa & Human & \\
\hline & 234 & United Kingdom & Sewage & \\
\hline & ASC 122, ASC 126 & United Kingdom & Sewage & \\
\hline & ASC 101, ASC 103 & United Kingdom & Tannery & \\
\hline & ASC 327 & United States & Unknown & \\
\hline & ASC 184 & United Kingdom & Cow & Vollum \\
\hline & ASC 185 & United Kingdom & Cow & Vollum \\
\hline & ASC 328 & United States & Unknown & \\
\hline & NCTC 5444 & United Kingdom & Unknown & \\
\hline & ATCC 938 & United Kingdom & Human & \\
\hline \multirow[t]{8}{*}{2} & ASC 68, ASC 162, ASC 167 & United States & Cow & Ames \\
\hline & NCTC $10340^{\mathrm{T}}$ & United Kingdom & Cow & Vollum \\
\hline & ASC 69 & United States & Human & New Hampshire \\
\hline & ASC 182 & France & Unknown & Pasteur $r$ \\
\hline & ASC 27, ASC 28, ASC 29, ASC 30, ASC 31 & Africa & Cow & \\
\hline & ASC 65 & Brazil & Cow & \\
\hline & ASC 45 & United Kingdom & Cow & Sterne \\
\hline & ASC 60 & Africa & Elephant & \\
\hline \multirow[t]{2}{*}{3} & NCTC 8234, ASC 97, ASC 47 & Africa & Cow & Sterne \\
\hline & ASC 58 & Africa & Elephant & \\
\hline
\end{tabular}

avirulent forms could not be detected. In contrast, $B$. cereus and $B$. thuringiensis not only produced patterns different from that of $B$. anthracis but also exhibited strain-to-strain heterogeneity. More importantly, this method could not unequivocally identify specific differences between $B$. anthracis and morphologically similar $B$. cereus group isolates that phenotypically appear to be $B$. cereus. DNA homology studies (4) have indicated that the level of similarity between individual isolates of $B$. anthracis is more than $90 \%$, suggesting that the detection of polymorphisms or mutations within restriction enzyme sites, as revealed by DNA digestion, would be almost impossible unless gross rearrangements, deletions, or insertions were present.

When PCR fingerprinting with oligonucleotides having both arbitrary and specific sequences was used and when different annealing temperatures and $\mathrm{Mg}^{2+}$ concentrations were used, almost all of the patterns generated from the different $B$. anthracis isolates were identical. These patterns allowed $B$. anthracis to be specifically distinguished from other members of the $B$. cereus group. As observed with the restriction enzyme fragment patterns, PCR fingerprinting revealed a large degree of strain-to-strain heterogeneity in both $B$. cereus and $B$. thuringiensis and also revealed differences between $B$. anthracis and morphologically similar isolates. Such isolates exhibited a high degrees of band sharing with $B$. anthracis, but differences, mainly in the form of bands in addition to the bands in the standard $B$. anthracis profile, were readily distinguished in the fingerprints. These differences were independent of the virulence factor gene content in $B$. anthracis. The similarity of the profiles of certain $B$. cereus group isolates to the general $B$. anthracis profile suggests that these isolates are either (i) $B$. cereus strains that have a similar distribution of the M13 sequence in their genomes or (ii) avirulent $B$. anthracis isolates that represent a more heterogeneous member of the species. To date, heterogeneous isolates of $B$. anthracis have not been isolated from infections.

Penicillin susceptibility is one of the standard criteria used to confirm that an isolate is $B$. anthracis. It is interesting that a penicillin-resistant isolate (Fig. 3, lane 14) produced one of the three standard $B$. anthracis profiles with this fingerprinting primer without altering the profile. Either this organism has acquired the gene(s) for penicillin resistance or an existing gene(s) has in some way become derepressed or activated.

The M13 fingerprinting probe consensus sequence was the only 1 of 12 oligonucleotide primer sequences that revealed differences among $B$. anthracis isolates. The PCR fingerprints obtained with this primer exhibited minor differences in a 400 - to 500 -bp region which allowed us to assign the isolates to three groups. No correlation between these groups and host or parasite relationship was demonstrated, suggesting that no species-specific strains exist for the initiation of infection. However, the method did distinguish the vaccine strains (NCTC 8234, ASC 47, and ASC 97) from the other cultures; this was independent of plasmid content. Some level of correlation between group and country of origin may be apparent from the data in Table 2, but it must be borne in mind that many cases of anthrax (irrespective of host species) are directly or indirectly acquired from imported animal products, such as animal hides, wool, and hair or feed and fertilizer ingredients. This is exemplified by isolates ASC 27 through ASC 31, which were derived from cows with anthrax at different locations throughout the United Kingdom and were traced to contaminated peanuts imported from West Africa (13).

The lack of great variation in geographically separated isolates could be due to the fact that there are few opportunities for changes to occur because of the lack of chances for cycling of the organism in the environment and poor survival when the organism is in competition with other microorganisms. The opportunity for variation may arise only during the infrequent cycles through host organisms or in the presence of ideal environmental conditions. These limitations may mean that $B$. anthracis has only recently evolved as an independent species.

$B$. anthracis-like members of the $B$. cereus group (such as ASC 112) produce fingerprints very similar to those of conventional $B$. anthracis strains. These isolates may represent a link between the members of the group and a common ancestor; all of the $B$. cereus group isolates fingerprinted with the M13 primer had several bands in common with $B$. anthracis, suggesting that some conservation of chromosomal organization occurred. This could be investigated 
further by investigating the sequences that are amplified between the M13 oligonucleotide primer sequences.

\section{REFERENCES}

1. Ash, C., and M. D. Collins. 1992. Comparative analysis of $23 \mathrm{~S}$ ribosomal RNA gene sequences of Bacillus anthracis and emetic Bacillus cereus determined by PCR-direct sequencing. FEMS Microbiol. Lett. 94:75-80.

2. Ash, C., J. A. E. Farrow, E. Dorsche, E. Stackebrandt, and M. D. Collins. 1991. Comparative analysis of Bacillus anthracis, Bacillus cereus, and related species on the basis of reverse transcriptase sequencing of $16 \mathrm{~S}$ rRNA. Int. J. Syst. Bacteriol. 41:343-346.

3. Atlas, R. M., and A. K. Bej. 1990 . Detecting bacterial pathogens in environmental water samples by using PCR and gene probes, p. 399-407. In M. Innis, D. Gelfand, D. Sninsky, and T. White (ed.), PCR protocols: a guide to methods and applications. Academic Press, New York.

4. Bohm, R., and G. Spath. 1989. The taxonomy of Bacillus anthracis according to the results of DNA-DNA hybridisation. Salisbury Med. Bull. 68(Special Suppl.):29-31.

5. Bowen, J. E., and P. C. B. Turnbull. 1992. The fate of Bacillus anthracis in unpasteurised and pasteurised milk. Lett. Appl. Microbiol. 15:224-227.

6. Cancilla, M. R., I. B. Powell, A. J. Hillier, and B. E. Davidson. 1992. Rapid genomic fingerprinting of Lactococcus lactis strains by arbitrarily primed polymerase chain reaction with ${ }^{32} \mathrm{P}$ and fluorescent labels. Appl. Environ. Microbiol. 58:1772-1775.

7. Carl, M., R. Hawkins, N. Coulson, J. Lowe, D. L. Robertson, W. M. Nelson, R. W. Titball, and J. N. Woody. 1992. Detection of spores of Bacillus anthracis using the polymerase chain reaction. J. Infect. Dis. 165:1145-1148.

8. Cowles, P. B. 1931. A bacteriophage for B. anthracis. J. Bacteriol. 21:161-166.

9. Davies, J. C. A. 1982. A major epidemic of anthrax in Zimbabwe. I. Cent. Afr. J. Med. 28:291-298.

10. Davies, J. C. A. 1983. A major epidemic of anthrax in Zimbabwe. II. Distribution of subcutaneous lesions. Cent. Afr. J. Med. 29:8-12.

11. Kaneko, T., R. Nozaki, and K. Aizawa. 1978. Deoxyribonucleic acid relatedness between Bacillus anthracis, Bacillus cereus and Bacillus thuringiensis. Microbiol. Immunol. 22:639-641.

12. Logan, N. A., J. A. Carman, J. Melling, and R. C. W. Berkeley. 1985. Identification of Bacillus anthracis by API tests. J. Med. Microbiol. 20:75-85.

13. Mansley, L. M. 1978. An outbreak of anthrax in the West Midlands. State Vet. J. 33:72-75.

14. Marmur, J. 1961. A procedure for the isolation of deoxyribonucleic acid from micro-organisms. J. Mol. Biol. 3:208-218.

15. McDonald, W. C., I. C. Felkner, A. Turetsky, and T. S. Matney. 1963. Similarity in base compositions of deoxyribonucleates from several strains of Bacillus cereus and Bacillus anthracis. J. Bacteriol. 85:1071-1073.

16. McKee, R. A., G. M. Gooding, S. D. Garrett, H. A. Powell, B. M. Lund, and M. Knox. 1991. DNA probes and the detection of food-borne pathogens using the polymerase chain reaction. Biochem. Soc. Trans. 19:698-701.
17. McMullin, D. E., and L. L. Muldrow. 1992. Typing of toxic strains of Clostridium difficile using DNA fingerprints generated with arbitrarily primed polymerase chain reaction primers. FEMS Microbiol. Lett. 92:5-10.

18. Miteva, V., A. Abadjieva, and R. Grigorova. 1991. Differentiation among strains and serotypes of Bacillus thuringiensis by M13 DNA fingerprinting. J. Gen. Microbiol. 137:593-600.

19. Miteva, V., A. Abadjieva, P. Ivanov, and R. Grigerova. 1990. M13 bacteriophage DNA as a probe for DNA fingerprinting in Gram-positive organisms. Syst. Appl. Microbiol. 13:350-353.

20. National Collection of Type Cultures and Pathogenic Fungi. 1989. Public Health Laboratory Service, London.

21. Pasteur, L. 1881. De l'attenuation des virus et de leur retour a la virulence. C. R. Acad. Sci. 92:429-435.

22. Plotkin, S. A., P. S. Brachman, M. Utell, F. H. Bumford, and M. M. Atchison. 1960. An epidemic of inhalation anthrax, the first in the twentieth century. Am. J. Med. 29:992-1001.

23. Sambrook, J., E. F. Fritsch, and T. Maniatis. 1989. Molecular cloning: a laboratory manual, 2nd ed. Cold Spring Harbor Laboratory Press, Cold Spring Harbor, N.Y.

24. Seki, T., C. Chang, H. Mikami, and Y. Oshima. 1978. Deoxyribonucleic acid homology of the genus Bacillus. Int. J. Syst. Bacteriol. 28:182-189.

25. Smith, N. E., R. E. Gordon, and P. H. A. Sneath. 1964. Type cultures and proposed neotype cultures of some species in the genus Bacillus. J. Gen. Microbiol. 34:269-272.

26. Sterne, M. 1937. The effects of different carbon dioxide concentrations on the growth of virulent anthrax strains. Pathogenicity and immunity tests on guinea-pigs and sheep with anthrax variants derived from virulent strains. Onderstepoort J. Vet. Sci. Anim. Ind. 9:49-67.

27. Titball, R. W., P. C. B. Turnbull, and R. A. Hutson. 1991. The monitoring and detection of Bacillus anthracis in the environment. J. Appl. Bacteriol. Symp. Suppl. 70:9S-18S.

28. Turnbull, P. C. B., J. M. Hofmeyr, A. M. T. McGetrick, and B. A. Oppenheim. 1986. Isolation of Bacillus anthracis, the agent of anthrax, in the Etosha National Park. Madoqua 14:321331.

29. Turnbull, P. C. B., R. A. Hutson, M. J. Ward, M. N. Jones, C. P. Quinn, N. J. Finnie, C. J. Duggleby, J. M. Kramer, and J. Melling. 1992. Bacillus anthracis but not always anthrax. J. Appl. Bacteriol. 72:21-28.

30. Vassart, G., M. Georges, R. Monsieur, H. Brocas, A. S. Lequarre, and D. Christophe. 1987. A sequence in M13 phage detects hypervariable minisatellites in human and animal DNA. Science 235:683-684.

31. Versalovic, J., T. Koeuth, and J. R. Lupski. Distribution of repetitive DNA sequences in eubacteria and application to fingerprinting of bacterial genomes. Nucleic Acids Res. 19: $6823-6831$.

32. Welsh, J., and M. McClelland. 1990. Fingerprinting genomes using PCR with arbitrary primers. Nucleic Acids Res. 18:72137218.

33. Williams, D. R., G. B. Rees, and M. E. Rogers. 1992. Observations on an outbreak of anthrax in pigs in north Wales. Vet. Rec. 131:363-366. 